\title{
LOS COMPUESTOS FENÓLICOS: UN ACERCAMIENTO A SU BIOSÍNTESIS, SÍNTESIS Y ACTIVIDAD BIOLÓGICA
}

\author{
THE PHENOLIC COMPOUNDS: AN APPROACH TO THEIR \\ BIOSYNTHESIS, SYNTHESIS AND BIOLOGICAL ACTIVITY
}

\begin{abstract}
D.A. Martin G.
Magister en Química. Laboratorio de Espectroscopia y Análisis Instrumental, Grupo de Investigación Química-Física Molecular y Modelamiento Computacional (QUIMOL), Facultad de Ciencias, Universidad Pedagógica y Tecnológica de Colombia (UPTC), Avenida Central del Norte, Tunja, Boyacá, Colombia.

dario.martin@uptc.edu.co
\end{abstract}

\section{Resumen}

Los compuestos fenólicos hacen parte de uno de los grupos más abundantes dentro de los metabolitos secundarios. Éstos se biosintetizan en las plantas por medio de rutas como la del ácido shikímico y la del acetato-malonato. En esta revisión se hace alusión a algunos grupos de polifenoles que se originan en los vegetales, por medio de dichas vías. Por la ruta del shikimato se pueden producir ácidos aromáticos como el ácido corísmico, prefénico, quínico, gálico que pueden ser bloques de construcción de muchos otros compuestos más funcionalizados. También a partir del ácido cinámico se puede obtener grupos tan diversos como las cumarinas, las chalconas, los flavonoles, flavanonas, ligninas, lignanos. Si se hace referencia a la ruta del acetato-malonato, se pueden generar fenoles simples como el ácido 6-metilsalícilo y otros derivados como el ácido orsellínico, y derivados de los mismos. Debido a la importancia aplicativa de los polifenoles, se han planteado algunos métodos químicos de síntesis para obtenerlos, en este documento se mencionan algunos. Gracias a su variedad en estructura química se presentan algunos resultados de investigaciones en donde se estudia la actividad biológica de los polifenoles, como reportes de actividades antioxidante, antimicrobiana, anticáncer, y otras actividades biológicas. Los compuestos fenólicos son un grupo muy diverso de metabolitos secundarios, que han sido y seguirán siendo estudiados, principalmente gracias a su actividad biológica, y a la necesidad de comprender sus biosíntesis en plantas y otros organismos.

Palabras Clave: Actividad biológica, biosíntesis de polifenoles, polifenoles, ruta del acetato-malonato, ruta del ácido shikímico, síntesis de polifenoles.

\section{Abstract}

The phenolic compounds are part of one of the most abundant groups within the secondary metabolites. These are biosynthesized in plants by means of routes such as shikimic 
acid and acetate-malonate. In this review, they are mentioned some groups of polyphenols that are originated in vegetables by means of these routes. Through the route of the shikimate they can produce aromatic acids such as chorismic acid, preferential, quinic, gallic acid that can be building blocks of many other more functionalized compounds. Also, cinnamic acid can obtain groups as diverse as coumarins, chalcones, flavonols, flavanones, lignins, lignans. If the reference is made to the acetate-malonate route, simple phenols such as 6-methylsalicylic acid and other derivatives such as orsellinic acid and derivatives can be generated. Due to the applicative importance of polyphenols, some chemical synthesis methods have been proposed to obtain them, some of which are mentioned in this document. Because of the variety of chemical structure some research results are presented where the biological activity of polyphenols was studied, as reports of antioxidant, antimicrobial, anticancer activities, and other biological activities. Phenolic compounds are a very diverse group of secondary metabolites, which have been and will continue to be studied, mainly through their biological activity, and the need to understand their biosynthesis in plants and other organisms.

Keywords: acetate-malonate pathway, biological activity, polyphenols biosynthesis, polyphenols synthesis, polyphenols, shikimic acid pathway.

\section{Introducción}

Las plantas sintetizan una gran cantidad de metabolitos primarios y secundarios. Los metabolitos primarios son moléculas que están directamente relacionados con funciones vitales de la planta, mientras que los secundarios son moléculas orgánicas que, a diferencia de los primarios, no parecen tener una función directa en procesos fotosintéticos, respiratorios, asimilación de nutrientes, transporte de solutos o síntesis de proteínas, carbohidratos o lípidos, y que se denominan metabolitos secundarios (también conocidos como productos secundarios, o productos naturales), y provienen todos de sustancias sintetizadas en el metabolismo primario, con algunas reacciones posteriores se forman las sustancias pertenecientes al metabolismo secundario (Figura 1) (Almaraz, Ávila, Delgado, Naranjo, \& Herrera, 2006) las rutas principales en la biosíntesis de los flavonoides son las rutas del ácido shikímico, poliacetatos y en menor medida el mevalonato. Los metabolitos secundarios además de no presentar una función definida en los procesos mencionados, difieren también de los primarios, en que ciertos grupos presentan una distribución no uniforme en el reino vegetal, es decir, no todos los metabolitos secundarios se encuentran en todos los grupos de plantas. Se sintetizan en pequeñas cantidades y no de forma generalizada, estando a menudo su producción restringida a un determinado género de plantas, a una familia, o incluso a algunas especies (Avalos \& Pérez, 2009). 


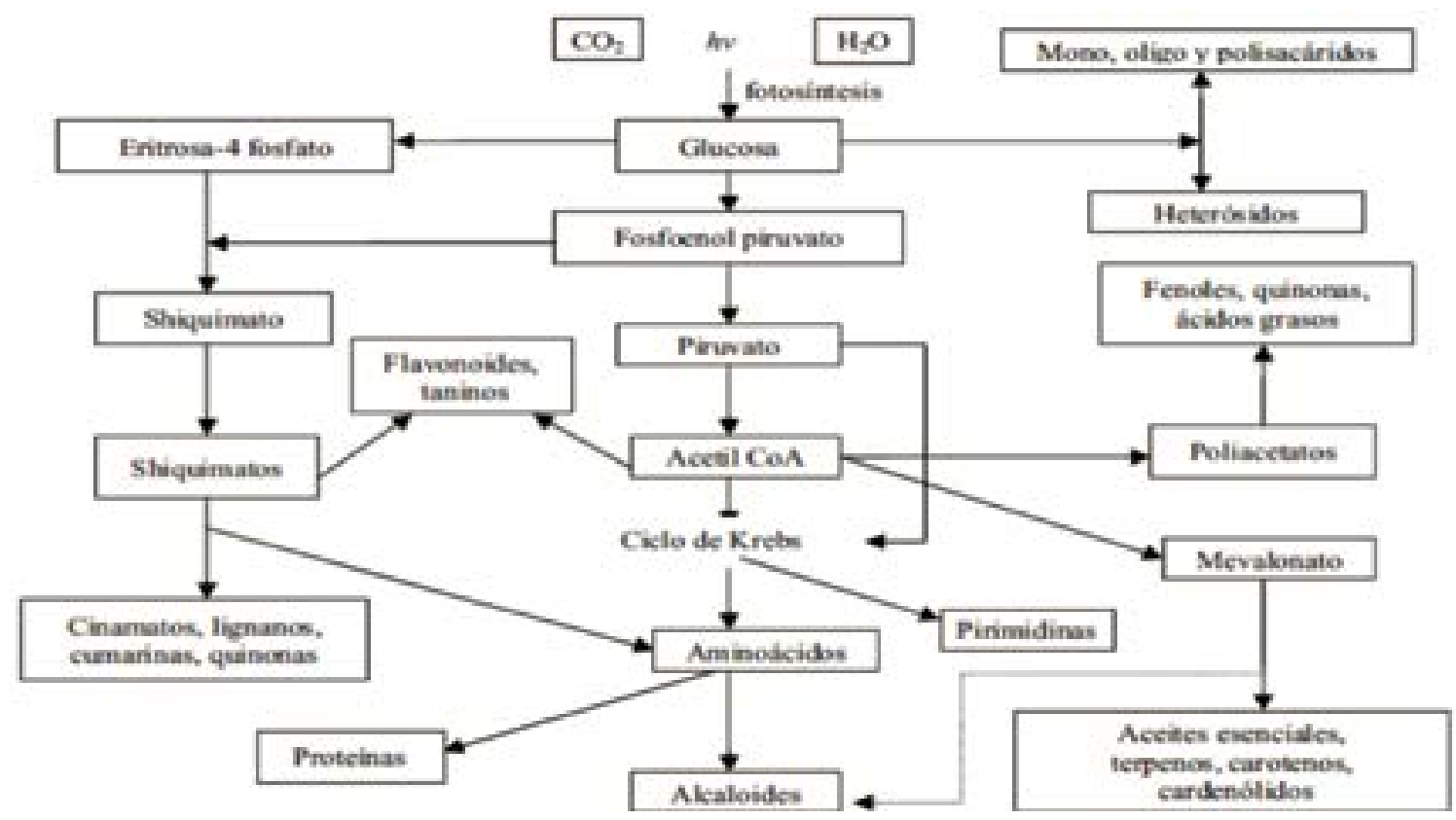

Figura 1. Relación entre metabolismo primario y secundario. Tomado de (Almaraz et al., 2006).

Los metabolitos secundarios se agrupan en cuatro clases principales: terpenos, compuestos fenólicos, alcaloides y glucósidos (Kozikowski, Tückmantel, Böttcher, \& Romanczyk, 2003). Aunque también hay en menor cantidad hidrocarburos, aldehídos, alcoholes, ácidos grasos, amidas, y ésteres, que son en gran medida responsables de muchos aromas en las plantas, posible actividad biológica, o son precursores de otros metabolitos secundarios (Croteau, Kutchan, \& Lewis, 2000). Además tienen diferentes rutas de biosíntesis dentro del reino vegetal, la ruta del ácido mevalónico, y la deoxi-xilulosa fosfato para terpenos (Eich, 2008), la ruta del ácido shikímico y la ruta del ácido malónico para polifenoles (Avalos \& Pérez, 2009; Isaza, 2007). Los alcaloides tienen una ruta metabólica compleja que implica las rutas del mevalonato, ácido shikímico (Loyola et al., 2004), ácido malónico y mezclas de las mismas (Ziegler \& Facchini, 2008) (Figura 1). Recientemente los investigadores recomiendan el consumo de una dieta rica en alimentos con altos contenidos de polifenoles, ya que, pueden tener efectos benéficos sobre patologías cardiovasculares, virales e incluso antineoplásicas (Tomás-Barberán, 2003).

Debido a la gran diversidad de productos naturales que se pueden sintetizar en las plantas, el objetivo planteado fue recopilar investigaciones concernientes a la síntesis y biosíntesis de polifenoles, caracterización y actividad biológica, haciendo un enfoque químico, pues éste grupo de metabolitos son de gran interés gracias a su marcada acción antioxidante, a su relación en procesos de interacción plantaherviboro, y como moléculas con muy buenos beneficios hacia la salud humana.

\section{Los compuestos fenólicos o fenilpropanoides}

Las plantas sintetizan una gran variedad de productos secundarios que contienen un grupo fenol. Estas sustancias reciben el nombre de compuestos fenólicos, polifenoles o fenilpropanoides y derivan todas ellas del fenol, un anillo aromático con un grupo hidroxilo 
(Isaza, 2007). Químicamente, los compuestos fenólicos son un grupo muy diverso que comprende desde moléculas sencillas como los ácidos fenólicos, hasta polímeros complejos como los taninos condensados y la lignina. Dentro de los compuestos fenólicos también se encuentran pigmentos flavonoides. Muchos de estos productos están implicados en las interacciones planta herbívoro (Avalos \& Pérez, 2009). Los flavonoides, también conocidos como bioflavonoides, forman un grupo de alrededor de 3,000 compuestos fenólicos que tienen una estructura química similar, dotándolos de propiedades funcionales importantes al ser consumidos. Estos metabolitos pueden encontrarse en todas las familias de plantas superiores y en casi todas las especies vegetales; es decir, que los flavonoides están presentes en todas las frutas, verduras y hierbas aromáticas. Se entiende por fenilpropanoides a compuestos de una amplia gama que biogenéticamente derivan del ácido shikímico en la llamada "ruta de los fenilpropanoides o del ácido shikímico", a través de la cual las especies vegetales biosintetizan más de 8000 compuestos fenólicos y polifenólicos cuya característica más relevante es su comportamiento antioxidante (Jovanovic, 2006). A continuación se mostrarán algunas rutas de biosíntesis para algunos de estos grupos y/o metabolitos secundarios pertenecientes a los compuestos fenólicos o polifenoles.

\subsection{Biosíntesis de polifenoles}

La ruta del ácido shikímico es la más importante para originar compuestos fenólicos, e inicia con el acoplamiento del fosfoenolpiruvato (PEP) y la D-eritrosa-4-fosfato, para obtener el ácido 3-deoxi-D- arabino-heptusolónico-7-fosfato (DAHP). Esta reacción tiene un mecanismo similar a una condensación de Claisen, aunque sucede catalizada enzimáticamente preferentemente. La eliminación de ácido fosfórico del DAHP se lleva a cabo por una oxidación que genera un enol, gracias a la presencia del NAD ${ }^{+}$, y se forma un intermediario que sufre un re arreglo para convertirse en el ácido 3-dehidroquínico, que en presencia del NADH y de la misma enzima que oxidó el DAHP, en este caso, reducirá el ácido 3-dehidroquinico a ácido quínico. El ácido shikímico es formado por deshidratación del ácido 3-dehidroquínico, formándose primero el ácido 3-dehidroshikímico, que sufre una reducción en presencia de NADPH (Figura 2) (Dewick, 2002).

Los ácidos protocatequinico y el gálico son ácidos fenólicos que se forman por deshidratación del ácido 3-dehidroshikímico, posterior enolización (protocatecuico) y una reducción con posterior tautomería cetoenólica (gálico), respectivamente. Por otra parte, el ácido shikímico en fosforilado en presencia de ATP, formando el ácido shikímico 3-fosfato, que se une a una molécula de fosfoenolpiruvato en medio ácido, reacción catalizada por la enzima 3-enolpiruvilshikimico-3-fosfato (EPSP) sintasa. El producto obtenido sufre una eliminación del grupo fosfato como ácido fosfórico, resultando así el ácido 3-enolpiruvilshikimico3-fosfato (EPSP). El ácido corísmico se forma por una eliminación, probablemente concertada, del ácido fosfórico del EPSP (figura 3). El ácido prefénico es formado gracias a una transposición de Claisen, del grupo enolpiruvato, catalizada por la enzima enolpiruvato transferasa. Por último, para la formación de fenilalanina, el ácido prefénico sufre unan descarboxilación, la eliminación de un grupo hidroxilo, y una sustitución del oxígeno cetónico por un grupo amino, para dar como resultado la L-fenilalanina (L-Phe) (Dewick, 2002), estas reacciones son catalizadas por una enzima descarboxilasa, una reductasa y una aminoliasa (Figura 3). 


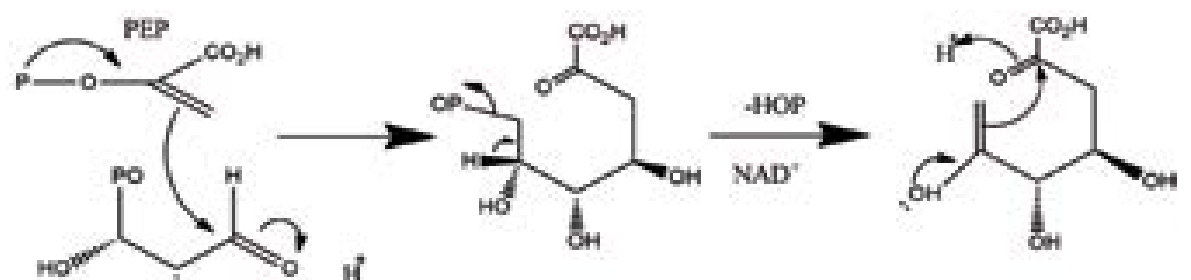

DAMP

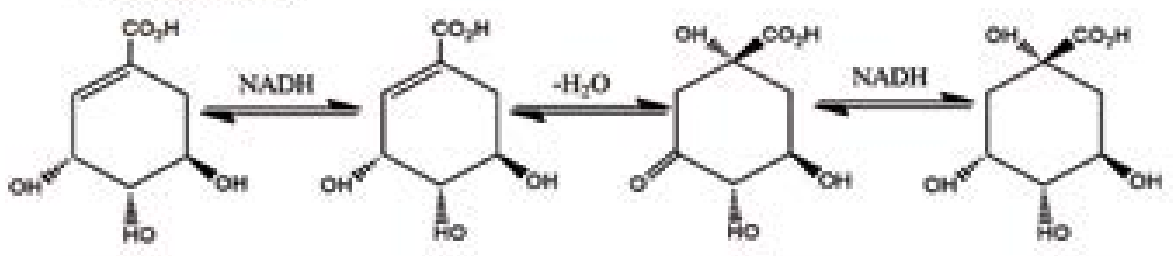

Áeido Shilimico

Acido 3-dethidrobhikintice

Ácido 3-Sthidriquinico

Ácido Quiniso<smiles>CCC(=O)c1ccc(O)c(O)c1</smiles>

Acido Protocanociteo
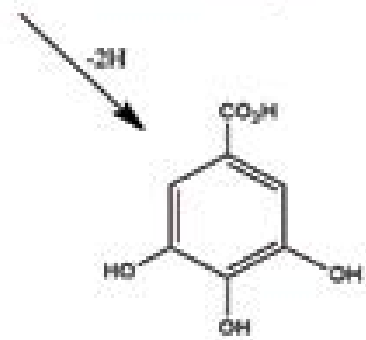

Ácido Gallico

Figura 2. Formación del ácido shikímico a partir de fosfoenolpiruvato y eritrosa 4-fosfato. Fuente de: (Dewick, 2002).<smiles>O=C(O)C1=C[C@@H](O)[C@H](O)[C@H](O)[C@H]1O</smiles>

Ácido Shikinico

Ácido Shikimico 3-Fosfato
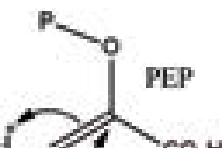
EPSP Sintasa<smiles>CCC[C@@H](O[C@H]1CC(C(=O)O)=C[C@@H](C)[C@@H]1C)[C@@H](O)CO</smiles>

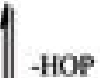

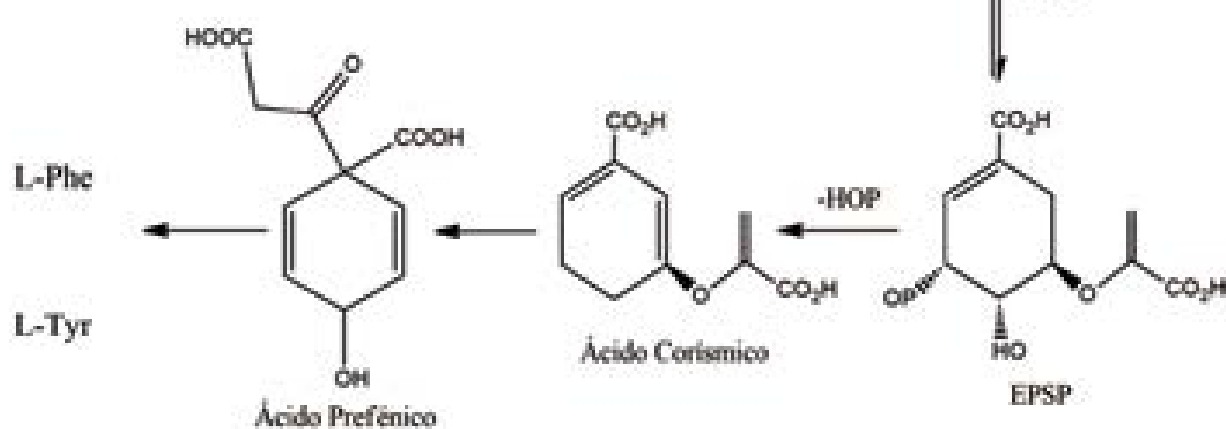

Figura 3. Formación del ácido corísmico y posterior conversión en aminoácidos aromáticos. Fuente de:(Dewick, 2002). 
En la (Ver en los anexos figura 4) se observa la continuación de la ruta de los fenilpropanoides, en donde la fenilalanina es desaminada por acción de la fenilalanina-amino liasa (PAL), formando ácido cinámico, que puede ser oxidado en presencia de NADPH, generando el ácido 4-cumárico, que también puede provenir de la L-tirosina. Este ácido 4-cumárico, puede ser oxidado a ácido cafeico, luego metilado en la posición meta produciendo ácido felúrico; en seguida se vuelve a oxidar y a metilar, dando como resultado el ácido sináptico. Todas las oxidaciones son en presencia de NADPH y las metilaciones catalizadas por la enzima adenosil metionina. Los tres ácidos pueden ser reducidos a alcohol cumarílico, coniférico y sinapílico respectivamente, catalizadas por el NADPH y la coenzima A. Estos alcoholes son los bloques de construcción de los lignanos y las ligninas (Dewick, 2002; Jovanovic, 2006).

Otro grupo de compuestos bastante importante dentro de los compuestos fenólicos son las cumarinas (Saigne et al., 2006), éstas se biosintetizan a partir del ácido cinámico, que se oxida en presencia de NADPH a ácido 2 y 4-cumárico (Figura 5). Posteriormente el ácido 2-cumárico sufre una isomerización de configuración $E$ a $Z$, catalizada por la enzima ácida 2-cumárico isomerasa, pues dicha configuración es más estable. La formación de la cumarina se realiza gracias a una ciclación intramolecular, conocida como lactonización (Dewick, 2002), en donde los pares libres del oxígeno hidroxílico atacan al carbonilo deficiente en electrones del grupo ácido, ciclando la molécula y liberando agua.

Si la ruta es con el ácido 4-cumárico (Figura 5), el primer paso ya no es la isomerización, sino una hidroxilación en posición 2 , para generar el ácido 2,4-dihidroxicinámico, que luego si sufre la isomerización de configuración $E$ a $Z$, y la condensación intramolecular (lactonización) para generar la umbeliferona, que es hidroxilada nuevamente en posición 6 para formar la escuiletina. La esculetina es eterificada en la posición 6 para dar escopoletina, y ésta por O-glicosidación originar la escopolina. Las cumarinas son compuestos que son utilizados como venenos, y aceleran la fermentación de la levadura (Valencia-Ortiz, 1995), además, en la naturaleza puede ser derivatizadas en cientos de compuestos (Herbert, 1989).

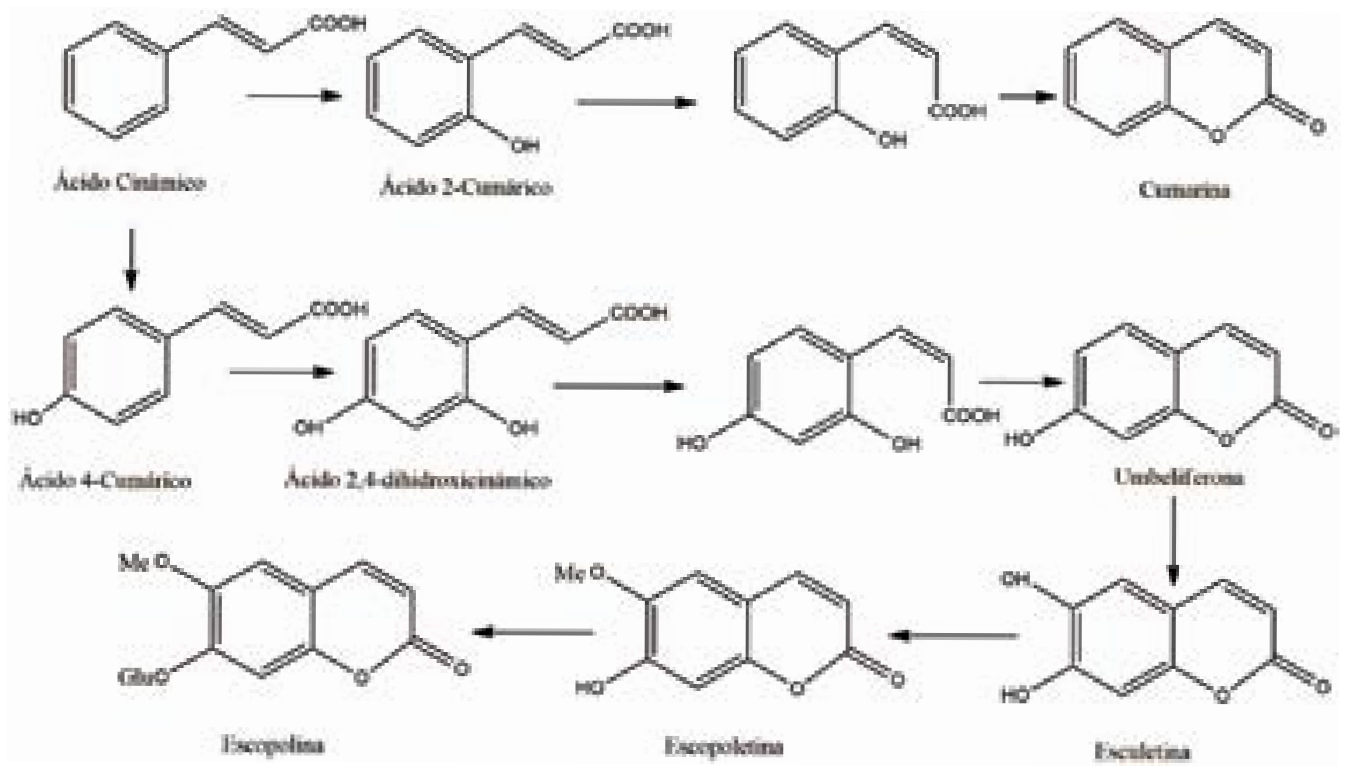

Figura 5. Biosíntesis de algunas cumarinas a partir del ácido cinámico.

Fuente de:(Dewick, 2002). 
Como ya se mencionó anteriormente, los compuestos fenólicos o fenilpropanoides son un grupo muy diverso, dentro de ellos también se encuentran las chalconas, que se originan en las plantas por un acoplamiento del 4-hidroxicinamoil-CoA con 3 moléculas de malonil-CoA (figura 6), que da forma a un intermediario que puede ser, o no, reducido en presencia de una reductasa y NADPH. Estos intermediarios sufren una reacción tipo Claisen, catalizada por chalconas sintasa, formando las chalconas (Herbert, 1989). Además de la biosíntesis de chalconas, en la figura 6 también se encuentran los estilbenos y flavanonas. Los primeros se forman por una reacción tipo aldólica del intermediario formado al acoplar las 3 moléculas de malonil-CoA con 4-hidroxicinamoil-CoA, catalizada por la estilbeno sintasa; mientras que las flavanonas se sintetizan a partir de las chalconas, mediante reacciones que involucran ataques nucleofílicos de los hidroxilos al sistema a y $\beta$ insaturado de las chalconas (Dewick, 2002).

Hasta acá se ha hecho referencia a la biosíntesis de compuestos fenólicos a partir de la ruta del ácido shikímico, ya que es la ruta más importante, y que conduce a la mayoría de ellos, pero también se pueden generar fenoles simples a partir de la ruta del acetato-malonato. En la figura 7 (Anexo) se ejemplariza la biosíntesis de algunos compuestos fenólicos a partir de la ruta del acetato-malonato. El primer paso es la unión de una molécula de acetil-CoA y tres de malonil-CoA para originar un $\beta$-policetoester, que puede seguir dos vías. En la vía A la ionización del a-metileno permite la adición (reacción aldólica) al carbonilo presente una distancia de seis carbonos a lo largo de la cadena, dando el alcohol terciario. La deshidratación se produce como en la mayoría de las reacciones químicas aldólicas, dando el alqueno, y seguido de una enolización para alcanzar la estabilidad conferida por el anillo aromático. El enlace tioéster (a la coenzima $A$ o ACP) se hidroliza para producir ácido orsellinico (Dewick, 2002; Herbert, 1989). Si en cambio la biosíntesis sigue la ruta $B$, el policétido se pliega de tal manera que permite una reacción de Claisen, que, aunque de manera mecánica análoga a la reacción aldólica, se termina con la expulsión del grupo saliente tiol, y la liberación directa de la enzima. La enolización de la ciclohexatriona produce la floracetofenona (Dewick, 2002; Valencia-Ortiz, 1995). En la figura 8 se explica la biosíntesis del ácido 6-metil salicílico por la vía del malonato.

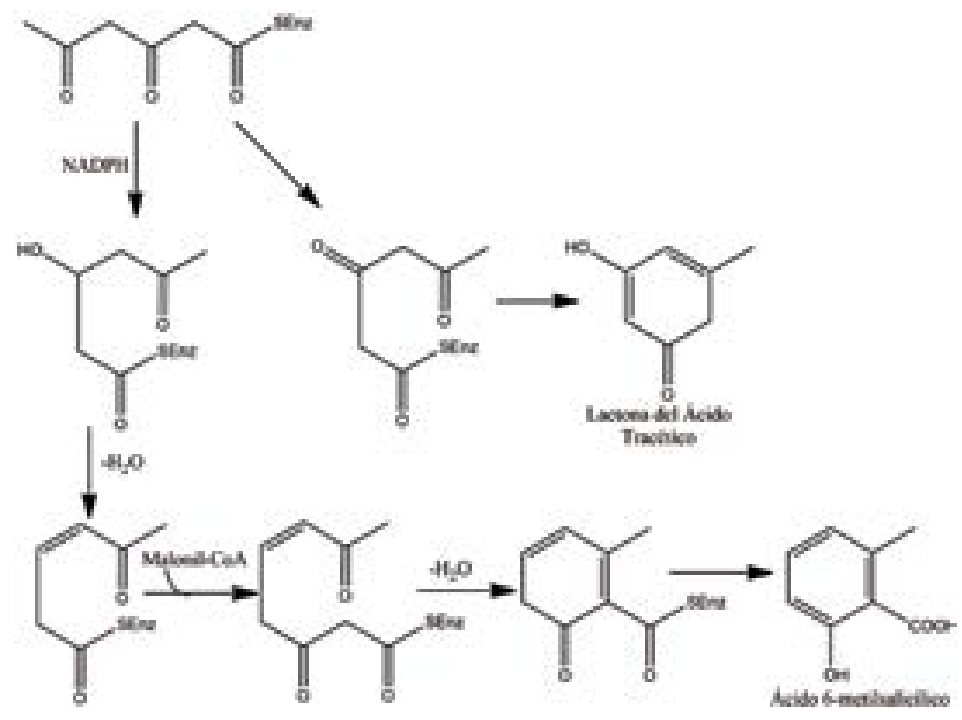

Figura 8. Biosíntesis del ácido 6-metilsalicílico.

Fuente: (Dewick, 2002) 
El ácido 6-metil salicílico difiere del ácido orsellínico por la ausencia de un grupo fenol en la posición 4. También se deriva de acetil-CoA y tres moléculas de malonil-CoA, y la función oxígeno se elimina durante la biosíntesis. El ácido orsellínico no está desoxigenado en sí mismo al ácido 6-metilsalicílico. La enzima ácida 6-metilsalicilico sintasa requiere NADPH como cofactor, y elimina la función de oxígeno mediante la reducción de una cetona a un alcohol, seguido de un paso de deshidratación (Figura 8). Hay evidencia de que la reducción / deshidratación ocurre realmente en un intermedio de seis carbonos a medida que la cadena crece, antes de la extensión final de la cadena. La evidencia importante para la reducción que ocurre en la etapa C6 como se muestra en la Figura 8 proviene de la formación de lactona de ácido triacético si se omite NADPH de la incubación enzimática (Holm et al., 2014).

\subsection{Síntesis de algunos compuestos fenólicos}

Hasta el momento se ha hecho un recuento de las rutas de biosíntesis de algunos compuestos fenólicos, pero desde hace algunos años, se han empezado a investigar en la síntesis orgánica de metabolitos de interés.

\subsubsection{Síntesis de chalconas}

Jeon, Yang, \& Jun (2011) plantean un método para la síntesis de cumarinas a partir de cinamatos de arilo, en medio ácido, tanto inorgánico como de Lewis. En la figura 8 se muestra la reacción general del método de obtención de las cumarinas, en donde se utiliza $\mathrm{TiCl}_{4}$ como catalizador. A partir de esta metodología se pueden obtener diversas cumarinas, dependiendo del sustituyente en posición R. En la figura 9 (Anexo) también se presenta el mecanismo de la reacción, en donde el ácido de Lewis rompe el cinamato generando un carbocatión y un compuesto formado por la unión del catalizador y el fenóxido. Dependiendo si en el método se realiza un control termodinámico o cinético se pueden obtener variantes en la estructura de la cumarina, además de presentar enolización de la estructura intermedia.

La condensación de Claisen-Schmidt es la reacción entre un aldehído aromático y una cetona. Se emplea un aldehído aromático ya que al no tener hidrógenos en posición alfa respecto al carbonilo, no puede dar lugar a la autocondensación, evitando la generación de productos no deseados. Se obtiene una cetona a, $\beta$-insaturada, la cual podría volver a reaccionar con el aldehído, por lo que en este caso la selectividad del catalizador vuelve a ser tan importante como su capacidad de conversión (Dip et al., 2016). El interés de esta reacción radica en que las chalconas obtenidas (figura 10) poseen propiedades antibacterianas, antifúngicas, antitumorales y antiinflamatorias y además, son reactivos intermedios en la síntesis de flavonoides y flavonas, que también presentan actividad biológica.

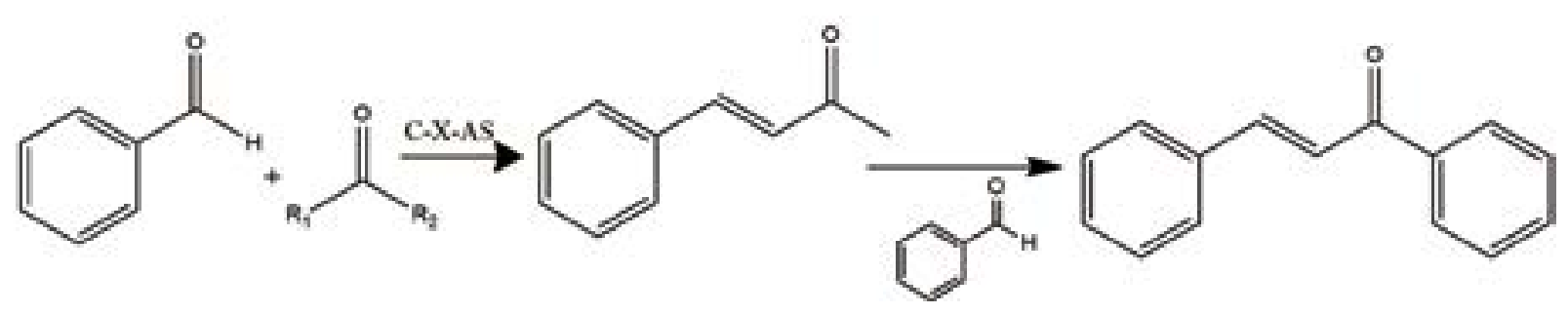

Figura 10. Síntesis de chalconas usando catalizadores carbonatados de carácter ácido. 


\subsubsection{Síntesis de arilcumarinas}

Dentro de los compuestos fenólicos de interés por su actividad biológica se encuentran las arilcumarinas. A continuación, se hace presentación de las variadas posibilidades para sintetizar 4-fenilcumarinas abarcando las siguientes alternativas:

Reacción de Pondorff: partiendo de ácidos fenilpropiólicos y fenoles se logra la síntesis de 4-fenilcumarinas con diversa sustitución. Las condiciones utilizadas para ello han incluido como agentes de condensación a los ácidos trifluoroacético (Aoki, Amamoto, Oyamada, \& Kitamura, 2005) y polifosfórico o Montmorillonita K-10, aplicándose en este último caso calefacción por medio de microondas. Entre los catalizadores utilizados para la condensación a 4-fenilcumarinas se encuentran el cloruro de platino y el tetracloroplatinato de potasio en trifluorometansulfonato de plata, o acetato de talio (III) (Oyamada \& Kitamura, 2006).

Reacción de Perkin: Esta estrategia implica partir de una $o$-hidroxibenzofenona y anhídrido acético para lograr la condensación en presencia de una base como acetato de sodio o de potasio (Garazd, Garazd, \& Khilya, 2005).

Reacción de Wittig: Otra alternativa a partir de $o$-hidroxibenzofenonas es por medio de la condensación con etoxicarboniltrifenilfosforano en benceno (Garazd et al., 2005).

Reacción de Houben-Hoesch: Si se parte de benzoílacetonitrilo y un fenol en presencia de cloruro de cinc y cloruro de hidrógeno se obtiene el clorhidrato de la iminocumarina, cuya hidrólisis ácida forma la 4-fenilcumarina correspondiente (Garazd et al., 2005).

4-Arilación de cumarinas: El método se basa en la arilación directa de 4-trifluorometansulfoniloxicumarinas por medio de reactivos organometálicos como ciertos estananos utilizando dioxano en presencia de tetraquis(trifenilfosfina)paladio o ioduro cuproso como catalizadores (Garazd et al., 2005).

Otro método de sustitución se basa en la reacción de Suzuki partiendo de una 4-cloro o 4-bromocumarina frente al ácido fenilborónico en presencia de $\mathrm{Pd}\left(\mathrm{PPh}_{3}\right)_{4}$ y una solución acuosa de carbonato de sodio (Garazd et al., 2005).

La síntesis de 4-arilcumarinas es reportada por Pérez Galera (2016), a través de una reacción de arilación tipo Heck seguida de una ciclación usando un catalizador de óxido de paladio (II) impregnado sobre magnetita y etanol como disolvente no tóxico y biorenovable (figura 11).

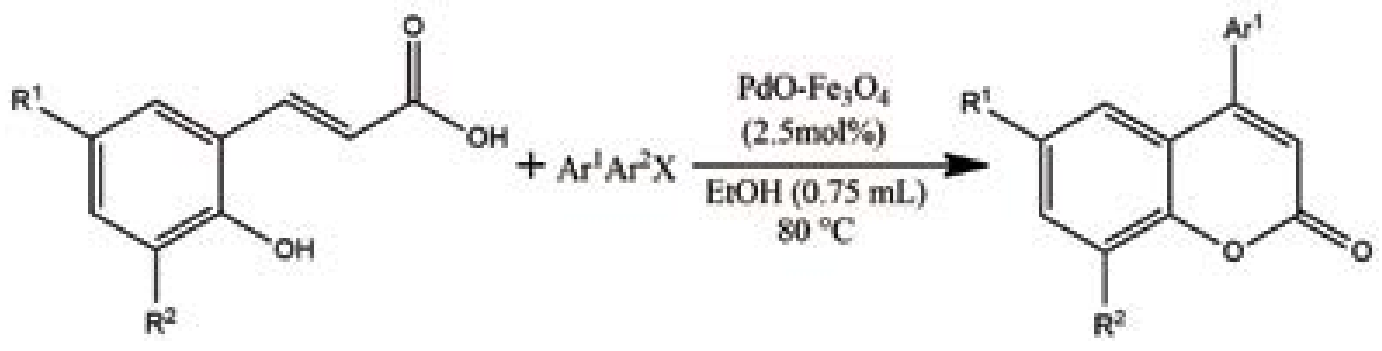

Figura 11. Síntesis de aril cumarinas con catalizadores de PdO soportados en magnetita.

Fuente: Pérez Galera (2016). 


\subsubsection{Síntesis de dihidrocumarinas}

Se han utilizado diferentes estrategias a fin de llevar a cabo la síntesis de dihidrocumarinas, las mismas se resumen a continuación:

Reducción de cumarinas: El método más difundido a nivel industrial para la preparación de 3,4-dihidrocumarinas es mediante la hidrogenación de cumarinas (Figura 12). La reducción se puede realizar con hidrógeno en presencia de catalizadores como paladio en solución alcohólica y presencia de sulfato de bario, o empleando níquel Raney en un rango de $160-200{ }^{\circ} \mathrm{C}$ en éter de petróleo a una presión que oscila enter 100-200 atm. (Barton \& Ollis, 1975).

Una reacción similar puede llevarse a cabo utilizando una fuente hidrogenante alternativa al hidrógeno, como el hidruro de aluminio y litio (Barton \& Ollis, 1975); también puede reducirse mediante formiato de amonio en presencia de un catalizador que permita la transferencia de hidrógeno como paladio soportado sobre carbón. La reacción de la 7-metoxicumarina a temperatura de reflujo de metanol en un lapso de 2 horas produce 7-metoxi-3,4-dihidrocumarina con un rendimiento del $90 \%$ Otra forma de lograr la reducción es por medio de reactivos organometálicos como compuestos de alquilmagnesio, alquillitio, alquilaluminio y dialquilcuprato de litio (Ganguly, Dutta, \& Datta, 2006).

También se ha ensayado la reducción por una vía biocatalítica, mediente el uso de cepas de Saccharomices cerevisiae, Pseudomonas orientalis y Bacillus cereus, trabajando entre 6 y 13 días en un medio acuso de peptona de caseína y glucosa (Häser, Wenk, \& Schwab, 2006). De esta forma se evitan condiciones de reacción más costosas o contaminantes.
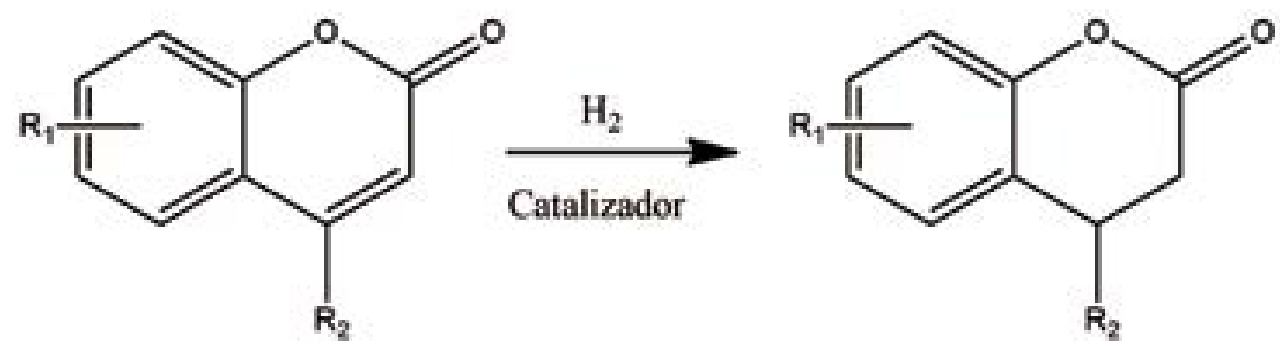

Figura 12. Síntesis de dihidrocumarinas por reducción de cumarinas.

Fuente: Barton and Ollis (1975).

Ciclación de ácidos melilóticos: La reducción de cumarinas ocurre con formación de ácido 3-(2-hidroxifenil)-propanóico (ácido melilótico) como intermediario y la posterior deshidratación del mismo (Figura 13). Esta última etapa puede realizarse sin involucrar la cumarina, partiendo directamente del ácido mencionado; se realiza a presión reducida en presencia de un $1 \%$ en peso de ácido cítrico (Häser et al., 2006). Esta misma reacción ha sido estudiada en condiciones más drásticas como por ejemplo frente a trifluoroacetato de talio (III) en ácido trifluoroacético, en presencia del eterato de trifluoruro de boro con rendimientos que oscilan entre $30-50 \%$. La reacción se realizó $-20^{\circ} \mathrm{C}$ en atmósfera inerte. 


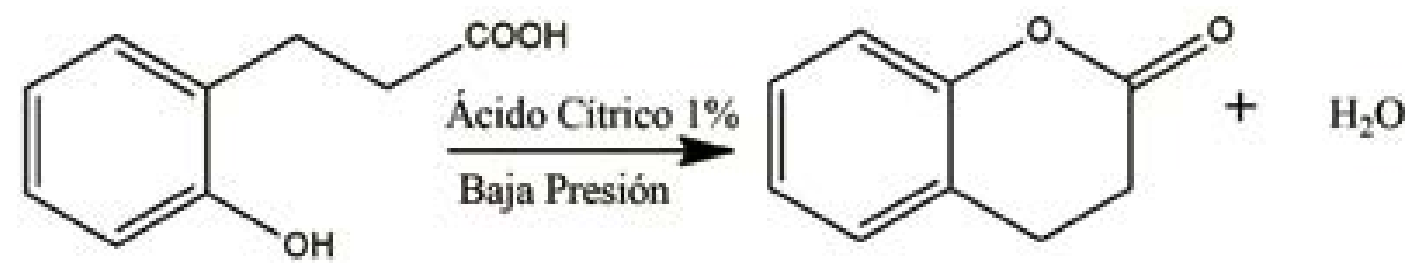

Figura 13. Síntesis de cumarinas a partir de ácidos melitólicos.

Fuente: Häser et al. (2006)

Reacción de Pondorff: Esta reacción es una variante de la reacción de von Pechmann en la que se parte de un ácido carboxílico $a, \beta$-insaturado frente a un fenol (Figura 14). Para que la reacción tenga lugar necesita de un catalizador (agente de condensación), para lo cual se han ensayado ácido sulfúrico, ácido polifosfórico, cloruro de hidrógeno, ácido trifluoroacético, eterato de trifluoruro de boro, resinas ácidas de intercambio iónico, y zeolitas. Esta reacción también se llevó a cabo en ausencia de solvente, bajo radiación de microondas, utilizando Montmorillonita K-10. Respecto a la catálisis de este tipo de reacciones, se han realizado experiencias con diferentes catalizadores sólidos como resinas Nafion (pura y mezclada con silicagel), Amberlyst 15 y zeolitas comerciales. También se ha sugerido una catálisis efectiva de esta reacción mediente acetato de paladio (II) en ácido trifluoroacético, pero resultados posteriores indican que la presencia de la sal no es realmente necesaria. La misma reacción puede adaptarse para la síntesis de cumarinas, partiendo de ácidos propiólicos en lugar de sus análogos olefínicos, obteniéndose generalmente rendimientos mayores (Aoki et al., 2005).

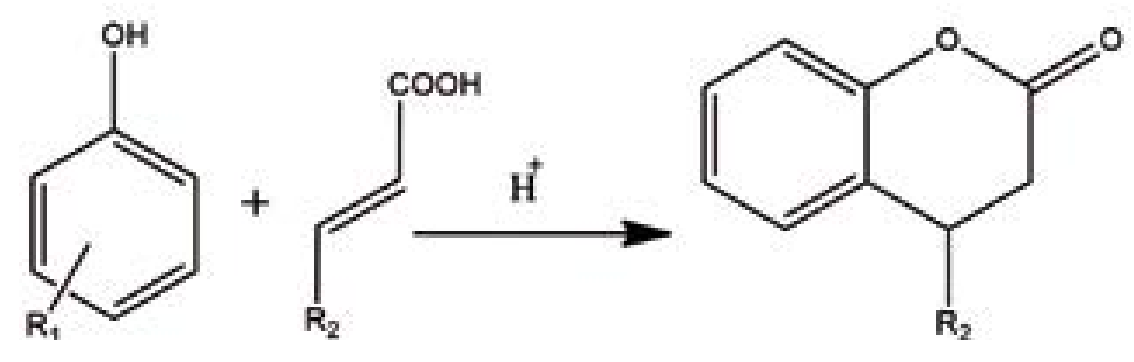

Figura 14. Síntesis de dehidrocumarinas vía reacción de Pondorff.

Fuente: Aoki et al. (2005).

Lactonización de acrilatos de arilo: Como la reacción de Pondorff implica la formación de los ésteres arílicos respectivos, las 3,4-dihidrocumarinas pueden sintetizarse partiendo del correspondiente acrilato de arilo mediante la lactonización del mismo en condiciones similares a las utilizadas para llevar a cabo la reacción de Pondorff (figura 15 ). Se han realizado ensayos que utilizan como agente de lactonización intramolecular la mezcla cloruro de rutenio (III)-trifluorometansulfonato de plata a $80^{\circ} \mathrm{C}$. También puede partirse del haluro de ácido en reemplazo del ácido acrílico, frente a los fenoles respectivos en presencia de disulfuro de carbono como solvente. Una tercera opción es partir de acrilatos de metilo sustituidos frente a un fenol y proceder según lo visto anteriormente, obteniéndose 
3,4-dihidrocumarinas, con la transesterificación de los acrilatos como etapa inicial. Se reporta que la misma reacción se practicó bajo condiciones de catálisis básica, lográndose rendimientos entre $40 \%$ y $60 \%$. Los autores mencionan que algún intento por realizar la reacción en presencia de cloruro de aluminio resultó infructuoso (Li, Foresee, \& Tunge, 2005).
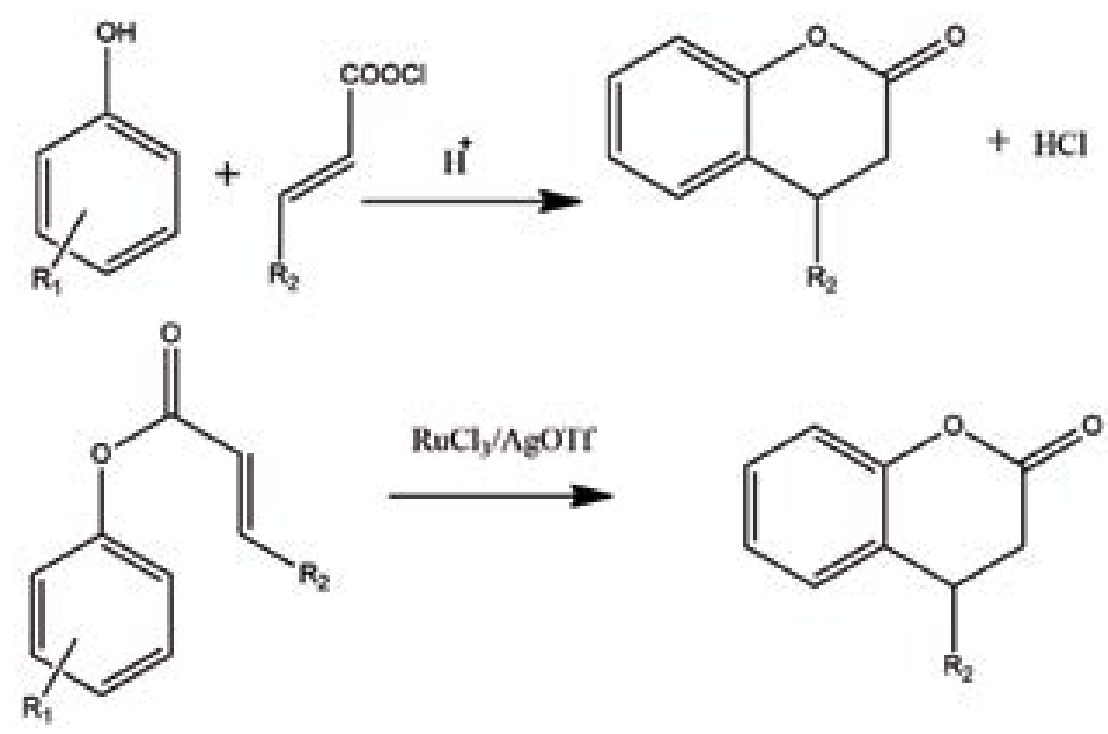

Figura 15. Representación general de procedimientos de lactonización.

Fuente: Li et al. (2005).

Reacción de Houben-Hoesch: Consiste en la reacción del fenol frente a nitrilos $a, \beta$ insaturados en presencia de cloruro de cinc, o cloruro de aluminio y cloruro de hidrógeno (Garazd et al., 2005). La reacción se lleva a cabo entre $120^{\circ} \mathrm{C}$ y $145^{\circ} \mathrm{C}$.

Acilación-alquilación de Friedel-Crafts: Los fenoles pueden hacerse reaccionar frente a derivados del ácido de Meldrum (2,2-dimetil-1,3-dioxano-4,6-diona) sustituidos en la posición 5 por un grupo alquilideno, utilizando trifluorometansulfonato de iterbio como catalizador ácido de Lewis (Dumas, Seed, Zorzitto, \& Fillion, 2007). Las condiciones de reacción incluyen al nitrometano como solvente, una temperatura de $100^{\circ} \mathrm{C}$ y un tiempo de reacción de 1,5 h, lográndose rendimientos con valores entre 70 - 91\%. La reacción procede según dos rutas posibles: a) C-alquilación/ O-acilación de Friedel-Crafts, b) C-acilación/ O-alquilación de FriedelCrafts, dependiendo del grado de sustitución del grupo alquilideno.

Adición oxidativa: Si se parte de un anillo aromático bencénico sustituido en posición orto por un grupo metoxietilenoxilo y por un grupo 3-butenilo, puede fomentarse la ruptura oxidativa del doble enlace mediante el uso de permanganato de potasio en presencia de un éter corona; un tratamiento posterior con eterato de tribromuro de boro en diclorometano a $0^{\circ} \mathrm{C}$ remueve el grupo metoxilo y promueve la ciclación, formando de esta manera una 3,4-dihidrocumarina (Wilkinson, Rossington, Ducki, Leonard, \& Hussain, 2006). 
Recientemente, Lee \& Scheidt (2015) han desarrollado una anulación formal asimétrica [4 + 2] altamente eficaz para la síntesis de dihidrocumarinas a través de una catálisis de NHC activada in situ (figura 16). Ambas especies electrófilas y nucleofílicas se generan in situ simultáneamente, por lo que los imidazoles de acilo facilitaron la formación rápida de un intermedio NHC-enolato para proporcionar los aductos de dihidrocumarina $[4+2]$.

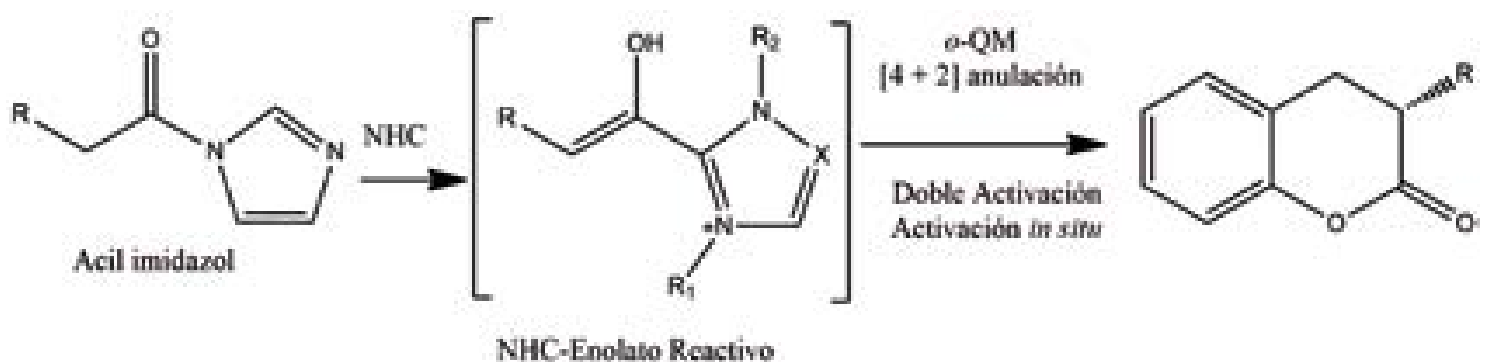

Figura 16. Estrategia de activación doble NHC.

Fuente: Lee and Scheidt (2015).

\section{Identificación y cuantificación de polifenoles}

Desde hace años se conoce de la presencia de muchos compuestos del grupo de los fenilpropanoides o compuestos fenólicos. Uno de los retos de los investigadores en fitoquímica ha sido lograr identificar, aislar y cuantificar dichos compuestos, por eso han hecho uso de varias técnicas analíticas que proporcionen distinta clase de información acerca de los mismos.

Para identificar polifenoles se utilizan varios métodos, como lo son resonancia magnética nuclear, de carbono e hidrógeno ( ${ }^{1} \mathrm{H}$ RMN, ${ }^{13}$ C RMN) (Rani \& Devanand, 2013; Saigne, Richard, Mérillon, \& Monti, 2006), con estas técnicas se puede conocer el tipo de carbonos e hidrógenos que posee una molécula, y por ende es muy importante para la elucidación estructural. La cromatografía de gases acoplada a detectores selectivos de masas (GC-MS) (Priyadharshini \& Sujatha, 2013; Quideau, Deffieux, Douat, \& Pouységu, 2011; Sagredo, Lorenzen, Casper, \& Lafta, 2011) es muy útil a la hora de identificar compuestos ya conocidos, pues se puede comparar los espectros de masas de cada compuesto con una biblioteca de productos naturales, y en dado caso que este compuesto sea nuevo, la espectrometría de masas (MS) proporciona información acerca del peso molecular, y de los patrones de fragmentación que arrojan bastante información acerca de la reactividad de estos compuestos.

La cromatografía liquida de alta eficiencia (HPLC), también es muy utilizada para identificar y cuantificar polifenoles. Hay reportes donde se utiliza acoplada a detectores ultravioleta visible de arreglo de diodo (HPLC-DAD) (Baño et al., 2003; Barros et al., 2013; Barros et al., 2012; Dragovic-Uzelac, Levaj, Mrkic, Bursac, \& Boras, 2007; Hale, Reddivari, Nzaramba, Bamberg, \& Miller Jr, 2008; Zadra et al., 2012), en donde se identifican compuestos en matrices grandes, con la ayuda de patrones, o con la comparación de los espectros UV-visible siempre y cuando se presenten multibandas de absorción, que serán características de cada 
compuesto, basados en las proporciones relativas entre las mismas. La cromatografía liquida acoplada a detectores UV-visible sin arreglo de diodo (HPLC-UV) (Dragovic-Uzelac et al., 2007; Kozikowski et al., 2003) también se reportan para identificar algunos compuestos fenólicos comparando los tiempos de retención con los de los estándares.

Para cuantificar contenidos totales de polifenoles se utiliza el método Folin-Ciocalteau, que se basa en la reactividad de los polifenoles con el reactivo de Folin-Ciocalteau (tusgtomolibdato y tugstofosfato) a pH básico, permitiendo una cuantificación espectrofotométrica en 730 nm (Mennella et al., 2010; Zadra et al., 2012), y se toma el ácido gálico para hacer la curva de calibración. Aunque el método de Folin para la cuantificación de polifenoles totales da una idea acerca de la cantidad de ellos, en los últimos años se ha tratado de cuantificar metabolitos específicos. Es así como se han hecho cuantificaciones de acidos cafeico, felurico, cumárico (Barros et al., 2012), clorogénico (Hale et al., 2008; Muñoz Jáuregui et al., 2014), rosmárico por por HPLC-DAD-ESI/MS (Zadra et al., 2012) y HPLC-UV (Damašius, Venskutonis, Kaškonienè, \& Maruška, 2014), ácido cumárico, felúrico por HPLC-UV (Dragovic-Uzelac et al., 2007; Kozikowski et al., 2003) y LC-MS/MS (Bursal, Köksal, Gülçin, Bilsel, \& Gören, 2013), y muchos otros polifenoles por HPLC-DAD (Moreno, Scheyer, Romano, \& Vojnov, 2006).

\section{Actividad biológica}

Gracias al poder antioxidante que tienen los polifenoles, éstos presentan una variedad de efectos benéficos, como lo son la capacidad antioxidante, antimicrobiana, anticáncer, antiinflamatoria, entre otras. En esta sección se hará un muy breve recuento de algunas de las muchas investigaciones que hay al respecto, centrado en los mecanismos químicos o biológicos que permiten que los polifenoles tengan dicha función.

\subsection{Actividad antioxidante}

La actividad antioxidante está relacionada mayoritariamente a la presencia de polifenoles o compuestos fenólicos (de Souza et al., 2014; Martins, Barros, \& Ferreira, 2016; Skrovankova, Sumczynski, Mlcek, Jurikova, \& Sochor, 2015; Sumczynski, Kotásková, Družbíková, \& Mlček, 2016; Tsao, 2010), gracias a la capacidad que tienen dichos compuestos de atrapar, o inhibir la producción de radicales libres (Brown, 2005; Quideau et al., 2011; Shahidi \& Ambigaipalan, 2015). Los flavonoides actúan fundamentalmente como tampones, y capturan radicales libres para generar el radical flavínico, mucho menos reactivo, ya que en él los electrones desapareados están más deslocalizados (Figura 16). Además, flavonoles como la quercetina, y otras flavanonas pueden quelar iones metálicos de transición como el hierro o el cobre, evitando así la formación de las especies reactivas de oxígeno producidas por la reacción de Fenton (Figura 16) (Martínez-Flórez, González-Gallego, Culebras, \& Tuñón, 2002; Quiñones, Miguel, \& Aleixandre, 2012). 


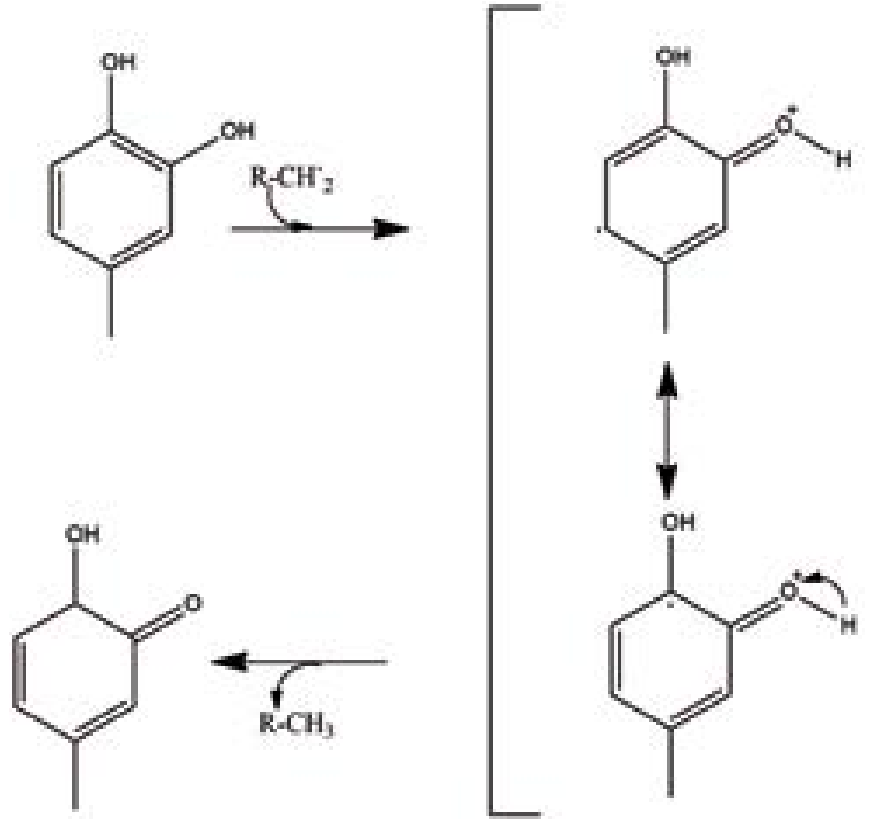

Figura 17. Mecanismo químico de la acción antioxidante de los polifenoles.

Adaptado de Quiñones et al. (2012)

A continuación se resumen algunos estudios realizados por investigadores que probaron extractos con altos contenidos de polifenoles, y otros metabolitos secundarios, para disminuir la formación, concentración y actividad de agentes radicalarios que pueden afectar la salud humana.

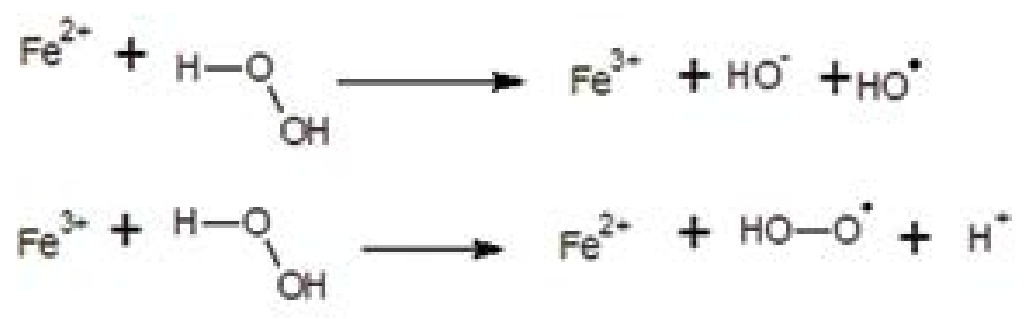

Figura 18. Mecanismo de la reacción de Fenton. Adaptado de Quiñones et al. (2012).

Brown (2005) reporta que variedades de papa (Solanum tuberosum) tiene altos contenidos de luteína, zeaxantina, violoxantinas, vitamina $C$, ácidos fenólicos $y$ en menor cantidad a y $\beta$-carotenos, que son los responsables de bajar los contenidos de glucosa y colesterol, e impedir la peroxidación de los lípidos. El tomate (S. lycopersium) también es conocido por la presencia de compuestos fenólicos y de carotenos y licopeno, que le confieren actividad antioxidante, encontrándose valores de 145 $\mu \mathrm{g} / \mathrm{ml}$ y $498 \mu \mathrm{g} / \mathrm{ml}$ de DHHP (Choi et al., 2011).

La planta de S. guariticum presenta altos contenidos de fenoles totales, flavonoides, taninos condensados y en menor cantidad alcaloides. Gracias a dicha composición Zadra et al. (2012)investigaron el efecto de extractos de acetato de etilo, etanol, butanol y cloroformo como antioxidantes. Encontraron que la 
fracción de acetato de etilo fue más eficiente como antioxidante, con valores de concentración inhibitoria $\left(\mathrm{IC}_{50}\right)$ mayores en el patrón de ácido ascórbico, que con el extracto. Además, el extracto clorofórmico extrajo mayor concentración de flavonoides, taninos y alcaloides, mostrando una mayor reducción en la peroxidación de lípidos. Mennella et al. (2010) también reportan la acción antioxidante, y sobre la enzima polifenoloxidasa de extractos ricos en compuestos fenólicos aislados de $S$. melongena, y recomiendan la especie como potencial antioxidante.

Ricco et al. (2010) investigaron los contenidos de polifenoles (fenoles totales, flavonoides totales y ácidos hidroxicinámicos totales) y determinaron la capacidad antioxidante de Aloysia gratissima var. gratissima (Gill. Et Hook) Tronc., Aloysia gratissima var. schulziana (Moldenke) Botta, Aloysia polystachya (Griseb.) Moldenke and Lippia integrifolia. L. integrifolia fue la especie con mayor contenido de fenoles totales y $A$. polystachya la menor. En el análisis de los hidroxicinámicos, $A$. polystachya fue la que mayor concentración mostró. En cuanto a los flavonoides, $A$. polystachya fue la que mostró menor concentración en tanto que $A$. gratissima var. schultziana fue la más rica en estos compuestos. A. polystachya es la especie que presenta los menores valores de actividad antioxidante, seguida por $A$. gratissima var. gratissima y A. gratissima var. schulziana, mientras que $L$. integrifolia es la especie con mayor actividad antioxidante, en correlación con los valores de polifenoles totales.

Moreno et al. (2006) reportan el uso de extractos de Rosmarinus officinalis como potentes antioxidantes. Avella et al. (2008) cuantificaron el contenido de polifenoles totales, y la actividad antioxidante mediante DPPH en 13 malezas de la región de México, encontrando que algunas de ellas podían ser utilizados como antioxidantes. El propóleo también es una fuente rica de polifenoles, por eso Palomino et al. (2009) cuantificaron los polifenoles en estas matrices y determinaron su acción antioxidante, encontrando que son antioxidantes potenciales, usando métodos ABTS, DPPH y FRAP.

Recientemente, Vega et al. (2017) determinaron el contenido de polifenoles totales de las muestras de cafés puros y mezclados reportando en el rango de 28.60 a 46.82 y 11.17 a $16.10 \mathrm{mg} \mathrm{GAE} / \mathrm{g}$, respectivamente. El contenido de flavonoides fue de 22.16 a 38.29 y 9.36 a $14.92 \mathrm{mg}$ equivalentes de catequina/g, respectivamente y la actividad antioxidante estuvo en el rango de 0.11 a 0.20 y 0.025 a 0.061 $\mathrm{mmol}$ trolox $(\mathrm{TE}) / \mathrm{g}$, respectivamente. Estos resultados permitieron a los autores concluir que los de polifenoles totales son componentes que aportan un porcentaje importante de la capacidad antioxidante del café. En otro estudio en alimentos se evaluó la actividad antioxidante de las pulpas Rubus glaucus B, Vaccinium floribundum $\mathrm{K}$ y Beta vulgaris $\mathrm{L}$; los resultados de la prueba de actividad antioxidante presentaron valores de IC $_{50}$ mediante la técnica de DPPH en el rango de 53,33 - 141,88 $\mu \mathrm{g} / \mathrm{mL}$, lo cual está directamente relacionado con el contenido de fenoles (Torrenegra Alarcón et al., 2016).

Los flavonoides y demás compuestos fenólicos cuando son ingeridos se metabolizan hasta ácidos fenólicos, que se clasifican en benzoicos, fenilacéticos y cinámicos, principalmente. Mediante métodos "in vitro" (ABTS y FRAP) Surco-Laos et al. (2016) determinaron la capacidad antioxidante de los ácidos fenólicos de interés metabólico potencial. Los valores obtenidos variaron según la reacción química implicada y la estructura de los compuestos, en la cual influye el número de radicales, su posición en el anillo bencénico con relación al 
grupo carboxílico y la longitud de la cadena de este último. Compuestos como los ácidos ferúlico, elagico, galico, caféico y sináptico, y la miricetina son los responsables de la actividad antioxidante de extractos de manzana estrella morada (Chrysophyllum cainito L.), anacardo amarillo y anacardo rojo (Anacardium occidentale) (Moo-Huchin et al., 2015).

\subsection{Actividad antimicrobial}

La actividad antibacterial y antifúngica de los polifenoles se basa en la capacidad que tienen estos compuestos para inhibir el crecimiento, reproducción, respiración, y cualquier otra función vital de los microorganismos. Esta acción la realizan mediante mecanismos como la oxidación de enzimas específicas, que van a inhibir alguna función vital, como la respiración (Martínez-Flórez et al., 2002), también se reporta que estos los polifenoles se pueden unir a las cadenas de ADN interrumpiendo la reproducción o la síntesis de proteínas y elementos vitales para los microorganismos (Tomás-Barberán, 2003). Doss et al. (2009)

de extractos acuosos, metanólicos y acetónicos de S. tomentosum sobre Bacillus cereus, Staphylococcus epidermidus, S. aureus, Micrococcus kristinae, Streptococcus pyrogens, Escherichia coli, Salmonella pooni, Serratia marcescens, Pseudomonas aeruginosa, Klebsiella pneumonae. Encontraron que los extractos metanólicos y acetónicos fueron los que más inhibieron el crecimiento, con concentraciones mínimas inhibitorias del crecimiento bacterial del $5-6 \mathrm{mg} / \mathrm{ml}$ de extracto. Doss, Mubarack, and Dhanabalan (2009) probaron el efecto de taninos extraídos de hojas de $S$. trilobatum Linn sobre el desarrollo de cepas de $S$. aureus, St, pyrogens Salmonella typhi, P. aeruginosa, Proteous vulgaris y E. coli. Determinaron que S. aureus fue el más resistente a los taninos; la concentración mínima inhibitoria estuvo en plantean que algunos polifenoles tienen la capacidad de romper las membranas celulares de algunos microorganismos, produciendo una apoptosis celular. A continuación se mencionaran algunos estudios encaminados a determinar la actividad antimicrobiana de compuestos fenólicos, o de extractos ricos en ellos.

Moreno et al. (2006) reportan el uso de extractos acuosos, metanólicos y etanólicos de $R$. officinalis, ricos en polifenoles para controlar el crecimiento de bacterias gram negativas (Escherichia coli, Xanthomonas campestris pv campestris, Klebsiella pneumoniae y Proteus mirabilis) bacterias grampositivas (Staphylococcus aureus, Bacillus megaterium, Bacillus subtilis, Enterococcus faecalis) y hongos (Saccharomyces cerevisiae, Candida albicans, Picchia pastoris), haciendo uso de la técnica de difusión en agar. Encontraron buenos resultados contra las tres especies de hongos y $X$. campestris $p v$ campestris, K. pneumoniae y P. mirabilis.

Aliero \& Afolayan (2006) estudiaron el efecto

un rango de 1 a $2 \mathrm{mg} / \mathrm{ml}$ y la concentración bactericida entre 1.5 y $2 \mathrm{mg} / \mathrm{mL}$.

Taguri et al. (2004) investigaron el efecto antimicrobiano de compuestos como epigallocatequina, epigallocatequina-3-O-galato, punicalagina, ácido tánico, castalagina, prodelfinidina, geraniina, procianidinas, sobre serotipos de $S$. aureus, Salmonella, E. coli y varias especies de Vibrio. Encontraron concentraciones mínimas inhibitorias promedio de $192 \pm 91$ y $162 \pm 165$ $\boldsymbol{\mu} \mathrm{g} / \mathrm{ml}$, para $S$. aureus y Vibrio respectivamente, y valores mucho más altos para SalmoneIla y E.coli $795 \pm 590$ y $1519 \pm 949 \mu \mathrm{g} / \mathrm{mL}$. En otro estudio, realizado por Varga et al. (2015) se informa del poder antimicrobiano de aceites esenciales de 4 especies de Thymos ricos en ácidos rosmarínico y caféico, narinenina, 
dehidroquercetina contra microorganismos como $P$. aeruginosa, Cronobacter sakazakii, Listeria innocua, Streptococcus pyogenes, C. albicans y $S$. cerevisiae; encontrando que los aceites de Thymus serpyllum, Thymus pulegioides y Thymus glabrescens fueron activos contra todos los microrganismos usados.

La actividad antibacteriana de los extractos ricos en compuestos fenólicos totales, de variedades de Hibiscus sabdariffa fue analizada contra microorganismos Gram-negativos (Escherichia coli, Salmonella enteritidis) y Grampositivos (Staphylococcus aureus, Micrococcus luteus), demostrando que los extractos de etanol fueron efectivos contra todas las cepas bacterianas probadas, mostrando una mayor efecto contra bacterias Gram-positivas (Borrás-Linares et al., 2015). Extractos acetónicos con gran diversidad de polifenoles en distintas especies de plantas son reportados como inhibidores de crecimiento de diferentes especies de microorganismos del género Candida con CMI de 0.01 a 200 mg/mL (Martins, Barros, Henriques, Silva, \& Ferreira, 2015). Los derivados de quercetina, catequina y epicatequina, procianidina B2 y derivados de ácido clorogénico representan los compuestos más abundantes en todos los extractos de Hipericum cardonae, Hipericum myricariifolium, Hipericum laricifolium, Hipericum humboldtianum, Hipericum garciae, Hipericum carinosum, and Hipericum cuatrecasii; la actividad antifúngica se evaluó frente a un panel de aislados clínicos de hongos patógenos. Cuatro de los extractos ensayados fueron activos contra C. albicans $\left(\mathrm{CMI}_{50}<353,25 \mu \mathrm{g} / \mathrm{ml}\right)$ y cinco contra C. parapsilosis $\left(\mathrm{CMI}_{50}<1000 \mu \mathrm{g} / \mathrm{ml}\right.$ ) (Tocci et al., 2018).

\subsection{Actividad anticáncer}

Muchas investigaciones plantean la posibilidad de que los flavonoides tienen la capacidad de inhibir alguna función vital en las células cancerosas. Se han identificado muchos posibles mecanismos de acción para estos flavonoides en la prevención del cáncer, que incluyen la actividad estrogénica/antiestrogénica, antriproliferativa, inducción del bloqueo del ciclo celular de las células cancerosas en una fase determinada y apoptosis, prevención de la oxidación, inducción de los enzimas de detoxificación (enzimas de Fase I y Fase II) regulación del sistema inmune y cambios en la señalización celular (Birt, Hendrich, \& Wang, 2001). Se podría esperar que una combinación de estos mecanismos pueda ser la responsable del carácter preventivo del cáncer que tienen estos compuestos. Los polifenoles también pueden proteger frente al cáncer mediante su inhibición del daño oxidativo del ADN, oxidación que parece ser una importante causa de mutaciones que potencialmente podría ser reducida por los antioxidantes de la dieta. Los polifenoles, por su actividad antioxidante, que ha sido ampliamente demostrada in vitro, podrían prevenir esta oxidación si alcanzan aquellos tejidos donde estas oxidaciones se pueden producir (Tomás-Barberán, 2003).

Choi et al. (2011) analizaron contenidos fenólicos y la inhibición de células cancerosas de extractos de algunas variedades de tomate, y de alimentos procesados a base de tomate. Encontraron que extractos de tomate verde presentaban una mayor inhibición de células cancerígenas de pulmón, y a concentraciones más altas de extracto, inhibió también el crecimiento de células de linfoma.

En experimentos in vitro realizados por (Martínez-Flórez et al., 2002) se ha confirmado el papel protector de la quercetina, la cual ejerce efectos de inhibición frente a células cancerígenas en humanos: en colon, glándula mamaria y ovario, en región gastrointestinal y en la leucemia. Una posible explicación a estos efectos anticancerígenos podría derivarse del 
incremento que algunos flavonoides producen en las concentraciones intracelulares de glutatión a través de la regulación de la expresión de la enzima limitante en su síntesis. Asimismo, en lo que respecta a la prevención del cáncer de mama, podría deberse a su potente capacidad de inhibir la actividad de la aromatasa evitando de esta forma la conversión de andrógenos en estrógenos.

Los ácidos chebulínico y elágico mostraron un efecto inhibitorio en el crecimiento de células cancerosas del osteosarcoma humano (Saleem, Husheem, Härkönen, \& Pihlaja, 2002). Además, el ácido chebulínico también participa de la comunicación disfuncional involucrada entre las células del carcinoma cervical humano (Yi et al., 2006). Otros efectos del ácido chebulínico resultan ser su efecto inhibitorio sobre las células de la leucemia humana y su citotoxicidad contra células malignas como el adenocarcinoma y tumores mamarios, osteosarcoma, cáncer de próstata y adenocarcinoma de colon en humanos (Yi et al., 2006). Por otra parte, la lamellarina $\mathrm{H}$ también muestra algún tipo de actividad antitumoral, en particular contra el cáncer de pulmón en humanos (You, Yang, Wang, \& Li, 2005).

\subsection{Otras actividades biológicas}

También, como consecuencia de su acción antioxidante, los polifenoles poseen efectos vasodilatadores, antitrombóticos, antiinflamatorios y antiapoptóticos. Además de las propiedades vasodilatadoras que favorecen el control del tono arterial, se han descrito otras propiedades de los flavonoides que favorecen también su efecto cardioprotector. Los polifenoles poseen efectos antilipémicos y antiaterogénicos. Habría además que señalar, que algunos estudios han demostrado que estos compuestos también pueden inhibir la enzima convertidora de la angiotensina (ECA), y la inhibición de esta enzima justificaría también sus efectos vasodilatadores y cardioprotectores (Quiñones et al., 2012).

Durante los últimos 25-30 años, se han llevado a cabo diferentes estudios epidemiológicos en diferentes países en un intento de evaluar el efecto de los hábitos dietéticos en el desarrollo de enfermedades cardiovasculares. Estos estudios han examinado la dieta de individuos en la década de los sesenta y han registrado la mortalidad por infarto de miocardio durante los 25 años siguientes. En uno de estos estudios, utilizando técnicas analíticas modernas, se ha evaluado el promedio de la ingesta de flavonoides y otras sustancias fenólicas en 16 grupos que participaban en el conocido como Estudio de los Siete Países. Se encontró que la ingesta de flavonoides estaba inversamente asociada a la mortalidad por infarto de miocardio (Michaël GL Hertog et al., 1995). Además se llevaron a cabo varios estudios prospectivos sobre poblaciones concretas en las que se estudió el efecto de la dieta en las enfermedades coronarias y cerebrovasculares. Cuatro de ellos iban dirigidos a las enfermedades coronarias y se llevaron a cabo con poblaciones de Holanda (Michael GL Hertog, Feskens, Kromhout, Hollman, \& Katan, 1993), EE.UU. (Rimm, Katan, Ascherio, Stampfer, \& Willett, 1996) y Finlandia (Knekt, Jarvinen, Reunanen, \& Maatela, 1996)y uno sobre enfermedades cerebrovasculares en Holanda(Keli, Hertog, Feskens, \& Kromhout, 1996).

Otros estudios epidemiológicos han puesto de manifiesto una relación directa entre el consumo de té y las enfermedades cardiovasculares. En estos casos también se ha considerado que los efectos antioxidantes de los flavonoides del té, que incluyen la prevención del daño oxidativo del LDL, están entre los mecanismos potenciales que pueden estar detrás de este efecto protector (Kris-Etherton \& Keen, 2002). Otros 
posibles mecanismos que se han sugerido para estos efectos beneficiosos incluyen la atenuación de los procesos inflamatorios en la aterosclerosis, una reducción de la trombosis, la promoción de una función normal del endotelio, y un bloqueo de la expresión de las moléculas que controlan la adhesión celular. Los flavonoides del chocolate y del té (flavan-3-oles) también tienen un efecto antioxidante in vitro e in vivo aumentando la capacidad antioxidante del plasma y la reactividad de las plaquetas. Los datos disponibles parecen indicar que $150 \mathrm{mg}$ de estos flavonoides (cantidad presente en una taza de té de $235 \mathrm{~mL}$ hervida durante $2 \mathrm{~min}$ ) son suficientes para producir un rápido efecto antioxidante en el plasma y cambios en la prostaciclina in vivo (Langley-Evans, 2000).

\section{Retos y tendencias}

Actualmente la investigación en fitoquímica está encaminada a identificar, aislar y caracterizar compuestos sintetizados por las plantas, con lo que el estudio detallado de las rutas biosintéticas, así como el uso de procedimientos que involucren instrumentos analíticos y métodos de separación robustos, son un área prometedora, obteniendo como resultado en unos años, una explicación profunda sobre los mecanismos de acción de los polifenoles sobre distintas patologías, procesos y microorganismos. Adicional, la síntesis química está avanzando a pasos agigantados en la creación e implementación de procesos que permitan obtener a gran escala dichos compuestos, y utilizar tecnologías cada vez más limpias y con mejores resultados. Se espera que la mezcla de la fitoquímica y la síntesis orgánica permita derivatizar muchos de los compuestos de origen polifenólico, para potenciar así su actividad biológica.

\section{Conclusiones}

Hasta el momento se cuenta con bastante información acerca de las vías por las que se pueden producir metabolitos secundarios en las plantas, aunque es necesario investigar a fondo. Estas vías involucran una serie de reacciones que son muy generales en química orgánica, y otras que más bien son específicas para la producción de ciertos metabolitos. La explicación detallada que se realizó sirve como material de partida para investigar rutas para la producción específica de metabolitos, haciendo uso de la ingeniería genética, para controlar las etapas en la biosíntesis de los polifenoles, y dirigirla hacia un compuesto (o grupo de compuestos) de interés. De hecho, si se conocen bien dichas rutas, es posible plantear métodos químicos para producir polifenoles con aplicaciones potencialmente importantes.

\section{Literatura citada}

Aliero, A., \& Afolayan, A. (2006). Antimicrobial activity of Solanum tomentosum. African Journal of Biotechnology, 5(4), 369-372.

Almaraz, N., Ávila, J. A., Delgado, E. A., Naranjo, N., \& Herrera, J. (2006). El metabolismo secundario de las plantas, un nuevo concepto.

Aoki, S., Amamoto, C., Oyamada, J., \& Kitamura, T. (2005). A convenient synthesis of dihydrocoumarins from phenols and cinnamic acid derivatives. Tetrahedron, 61(39), 9291-9297.

Avalos, A., \& Pérez, E. (2009). Metabolismo secundario de plantas. REDUCA (Biología), 2(3).

Avella, D. M. G., García, C. A. O., \& Cisneros, A. M. (2008). Medición de fenoles y actividad antioxidante en malezas usadas para alimentación animal. Paper presented at the Memorias del Simposio de Metrología. Universidad Autónoma de Querétaro. Centro Nacional de Querétaro.

Baño, M. J., Lorente, J., Castillo, J., Benavente, O., del Río, J. A., Ortuño, A., . . . Gerard, D. (2003). Phenolic Diterpenes, Flavones, and Rosmarinic Acid Distribution during the Development of Leaves, Flowers, Stems, and Roots of Rosmarinus officinalis. Antioxidant Activity. Journal of Agricultural and Food Chemistry, 51(15), 4247-4253. doi: $10.1021 /$ jf0300745

Barros, L., Dueñas, M., Alves, C. T., Silva, S., Henriques, M., Santos-Buelga, C., \& Ferreira, I. C. (2013). Antifungal activity and detailed chemical 
characterization of Cistus ladanifer phenolic extracts. Industrial Crops and Products, 41, 41-45.

Barros, L., Dueñas, M., Dias, M. I., Sousa, M. J., Santos-Buelga, C., \& Ferreira, I. C. (2012). Phenolic profiles of in vivo and in vitro grown Coriandrum sativum L. Food Chemistry, 132(2), 841-848.

Barton, D., \& Ollis, W. D. (1975). Comprehensive Organic Chemistry (Vol. 4): Pergamon Pres, Oxford.

Birt, D. F., Hendrich, S., \& Wang, W. (2001). Dietary agents in cancer prevention: flavonoids and isoflavonoids. Pharmacology \& therapeutics, 90(2), 157-177.

Borrás-Linares, I., Fernández-Arroyo, S., ArráezRoman, D., Palmeros-Suárez, P., Del Val-Díaz, R., Andrade-Gonzáles, I., . . Segura-Carretero, A. (2015). Characterization of phenolic compounds, anthocyanidin, antioxidant and antimicrobial

activity of 25 varieties of Mexican Roselle (Hibiscus sabdariffa). Industrial Crops and Products, 69, 385-394.

Brown, C. (2005). Antioxidants in potato. American journal of potato research, 82(2), 163-172. doi: https://doi.org/10.1007/BF02853654

Bursal, E., Köksal, E., Gülçin, İ., Bilsel, G., \& Gören, A. C. (2013). Antioxidant activity and polyphenol content of cherry stem (Cerasus avium L.) determined by LC-MS/MS. Food research international, 51(1), 66-74.

Croteau, R., Kutchan, T. M., \& Lewis, N. G. (2000). Natural products (secondary metabolites). Biochemistry and molecular biology of plants, 1250-1318.

Choi, S.-H., Kim, H.-R., Kim, H.-J., Lee, I.-S., Kozukue, N., Levin, C. E., \& Friedman, M. (2011). Free Amino Acid and Phenolic Contents and Antioxidative and Cancer Cell-Inhibiting Activities of Extracts of 11 Greenhouse-Grown Tomato Varieties and 13 Tomato-Based Foods. Journal of Agricultural and Food Chemistry, 59(24), 1280112814. doi: 10.1021/jf202791j

Damašius, J., Venskutonis, P., Kaškonienè, V., \& Maruška, A. (2014). Fast screening of the main phenolic acids with antioxidant properties in common spices using on-line HPLC/UV/DPPH radical scavenging assay. Analytical Methods, 6(8), 2774-2779.

de Souza, V. R., Pereira, P. A. P., da Silva, T. L. T., de Oliveira Lima, L. C., Pio, R., \& Queiroz, F. (2014). Determination of the bioactive compounds, antioxidant activity and chemical composition of Brazilian blackberry, red raspberry, strawberry, blueberry and sweet cherry fruits. Food Chemistry, 156, 362-368.

Dewick, P. M. (2002). Medicinal natural products: a biosynthetic approach: John Wiley \& Sons.

Dip, A., Torres, E., Blanco, M., Arias, Q., Michalik, M., \& Vogel, C. (2016). Síntesis de chalconas preniladas potencialmente bioactivas mediante reacciones consecutivas de reordenamiento y condensación de Claise. Revista Cubana de Química, 28(3), 834-842.

Doss, A., Mubarack, H. M., \& Dhanabalan, R. (2009). Antibacterial activity of tannins from the leaves of Solanum trilobatum Linn. Indian Journal of Science and Technology, 2(2), 41-43.

Dragovic-Uzelac, V., Levaj, B., Mrkic, V., Bursac, D., \& Boras, M. (2007). The content of polyphenols and carotenoids in three apricot cultivars depending on stage of maturity and geographical region. Food Chemistry, 102(3), 966-975. doi: http://dx.doi.org/10.1016/j.foodchem.2006.04.001

Dumas, A. M., Seed, A., Zorzitto, A. K., \& Fillion, E. (2007). A general and practical preparation of alkylidene Meldrum's acids. Tetrahedron letters, 48(40), 7072-7074.

Eich, E. (Producer). (2008, 2008/05/01). Solanaceae and Convolvulaceae: Secondary Metabolites. Reactions Weekly. Retrieved from http:// dx.doi.org/10.2165/00128415-200812020-00097

Ganguly, N. C., Dutta, S., \& Datta, M. (2006). Mild and efficient deprotection of allyl ethers of phenols and hydroxycoumarins using a palladium on charcoal catalyst and ammonium formate. Tetrahedron letters, 47(32), 5807-5810.

Garazd, M., Garazd, Y. L., \& Khilya, V. (2005). Neoflavones. 2. Methods for synthesizing and modifying 4-arylcoumarins. Chemistry of natural compounds, 41(3), 245-271.

Hale, A. L., Reddivari, L., Nzaramba, M. N., Bamberg, J. B., \& Miller Jr, J. C. (2008). Interspecific variability for antioxidant activity and phenolic content among Solanum species. American journal of potato research, 85(5), 332-341. doi: $10.1007 /$ s12230-008-9035-1

Häser, K., Wenk, H. H., \& Schwab, W. (2006). Biocatalytic production of dihydrocoumarin from coumarin by Saccharomyces cerevisiae. Journal of agricultural and food chemistry, 54(17), 6236-6240. 
Herbert, R. B. (1989). The biosynthesis of secondary metabolites: Springer Science \& Business Media.

Hertog, M. G., Feskens, E. J., Kromhout, D., Hollman, P., \& Katan, M. (1993). Dietary antioxidant flavonoids and risk of coronary heart disease: the Zutphen Elderly Study. The Lancet, 342(8878), 1007-1011.

Hertog, M. G., Kromhout, D., Aravanis, C., Blackburn, H., Buzina, R., Fidanza, F., . . . Nedeljkovic, S. (1995). Flavonoid intake and long-term risk of coronary heart disease and cancer in the seven countries study. Archives of internal medicine, 155(4), 381-386.

Holm, D. K., Petersen, L. M., Klitgaard, A., Knudsen, P. B., Jarczynska, Z. D., Nielsen, K. F., . . . Mortensen, U. H. (2014). Molecular and chemical characterization of the biosynthesis of the 6-MSA-derived meroterpenoid yanuthone $D$ in Aspergillus niger. Chemistry \& biology, 21(4), 519-529.

Isaza, M. (2007). Taninos o polifenoles vegetales. Scientia et Technica, 1(33), 13-18.

Jeon, J.-H., Yang, D.-M., \& Jun, J.-G. (2011). Selective synthesis of 3,4-dihydrocoumarins and chalcones from substituted aryl cinnamic esters. Bulletin of the Korean Chemical Society, 32(1), 65-70.

Jovanovic, L. (2006). New synthetic approaches to 8, 5'-neolignans.

Keli, S. O., Hertog, M. G., Feskens, E. J., \& Kromhout, D. (1996). Dietary flavonoids, antioxidant vitamins, and incidence of stroke: the Zutphen study. Archives of internal medicine, 156(6), 637-642.

Knekt, P., Jarvinen, R., Reunanen, A., \& Maatela, J. (1996). Flavonoid intake and coronary mortality in Finland: a cohort study. Bmj, 312(7029), 478-481.

Kozikowski, A., Tückmantel, W., Böttcher, G., \& Romanczyk, L. (2003). Studies in Polyphenol Chemistry and Bioactivity. 4.1 Synthesis of Trimeric, Tetrameric, Pentameric, and Higher Oligomeric Epicatechin-Derived Procyanidins Having All-4 $\beta, 8$-Interflavan Connectivity and Their Inhibition of Cancer Cell Growth through Cell Cycle Arrest1. The Journal of Organic Chemistry, 68(5), 1641-1658. doi: 10.1021/jo020393f

Kris-Etherton, P. M., \& Keen, C. L. (2002). Evidence that the antioxidant flavonoids in tea and cocoa are beneficial for cardiovascular health. Current opinion in lipidology, 13(1), 41-49.
Langley-Evans, S. C. (2000). Consumption of black tea elicits an increase in plasma antioxidant potential in humans. International Journal of Food Sciences and Nutrition, 51(5), 309-315.

Lee, A., \& Scheidt, K. A. (2015). N-Heterocyclic carbene-catalyzed enantioselective annulations: a dual activation strategy for a formal [4+2] addition for dihydrocoumarins. Chemical Communications, 51(16), 3407-3410.

Li, K., Foresee, L. N., \& Tunge, J. A. (2005). Migratory decarboxylative coupling of coumarins: synthetic and... hydroarylation of benzylidene malonic esters JOurnal of Organic Chemistry, 70, 2881-2883.

Loyola, V. M., Sánchez, P., Canto-Canché, B., Gutiérrez-Pacheco, L. C., Galaz-Ávalos, R. M., \& Moreno-Valenzuela, O. (2004). Biosíntesis de los alcaloides indólicos. Una revisión crítica. Revista de la Sociedad de Química de México, 48(1), 67-94.

Martínez-Flórez, S., González-Gallego, J., Culebras, J. M., \& Tuñón, M. J. (2002). Los flavonoides: propiedades y acciones antioxidantes. Nutr Hosp, 17(6), 271-278.

Martins, N., Barros, L., \& Ferreira, I. C. (2016). In vivo antioxidant activity of phenolic compounds: Facts and gaps. Trends in Food Science \& Technology, 48, 1-12.

Martins, N., Barros, L., Henriques, M., Silva, S., \& Ferreira, I. C. (2015). Activity of phenolic compounds from plant origin against Candida species. Industrial Crops and Products, 74, 648-670.

Mennella, G., Rotino, G. L., Fibiani, M., D'Alessandro, A., Francese, G., Toppino, L., . . Lo Scalzo, R. (2010). Characterization of Health-Related Compounds in Eggplant (Solanum melongena L.) Lines Derived from Introgression of Allied Species. Journal of Agricultural and Food Chemistry, 58(13), 7597-7603. doi: 10.1021/jf101004z

Moo-Huchin, V. M., Moo-Huchin, M. I., Estrada-León, R. J., Cuevas-Glory, L., Estrada-Mota, I. A., OrtizVázquez, E., . . . Sauri-Duch, E. (2015). Antioxidant compounds, antioxidant activity and phenolic content in peel from three tropical fruits from Yucatan, Mexico. Food Chemistry, 166, 17-22.

Moreno, S., Scheyer, T., Romano, C. S., \& Vojnov, A. A. (2006). Antioxidant and antimicrobial activities of rosemary extracts linked to their polyphenol composition. Free radical research, $40(2), 223-231$.

Muñoz Jáuregui, A. M., Alvarado-Ortíz Ureta, C., 
Blanco Blasco, T., Castañeda Castañeda, B., Ruiz Quiroz, J., \& Alvarado Yarasca, Á. (2014). Determinación de compuestos fenólicos, flavonoides totales y capacidad antioxidante en mieles peruanas de diferentes fuentes florales. Revista de la Sociedad Química del Perú, 80(4), 287-297.

Oyamada, J., \& Kitamura, T. (2006). Synthesis of coumarins by Pt-catalyzed hydroarylation of propiolic acids with phenols. Tetrahedron, 62(29), 6918-6925.

Palomino, L. R., García, C. M., Gil, J. H., Rojano, B. A., \& Durango, D. L. (2009). Determinación del contenido de fenoles y evaluación de la actividad antioxidante de propóleos recolectados en el departamento de Antioquia (Colombia). Vitae, 16(3).

Pérez Galera, J. M. (2016). Impregnated Cobalt, Nickel, Copper and Palladium Oxides on Magnetite: Nanocatalysts for Organic Synthesis. PhD, Universidad de Alicante, España.

Priyadharshini, D. S., \& Sujatha, V. (2013). Antioxidant profile and GC-MS analysis of Solanum erianthum leaves and stem. A comparison. International Journal of Pharmacy and Pharmaceutical Sciences, 5(3), 652-658.

Quideau, S., Deffieux, D., Douat, C., \& Pouységu, L. (2011). Plant Polyphenols: Chemical Properties, Biological Activities, and Synthesis. Angewandte Chemie International Edition, 50(3), 586-621. doi: 10.1002/anie.201000044

Quiñones, M., Miguel, M., \& Aleixandre, A. (2012). Los polifenoles, compuestos de origen natural con efectos saludables sobre el sistema cardiovascular. Nutrición Hospitalaria, 27, 76-89.

Rani, P. U., \& Devanand, P. (2013). Bioactivities of caffeic acid methyl ester (methyl-(E)-3-(3,4dihydroxyphenyl)prop-2-enoate): a hydroxycinnamic acid derivative from Solanum melongena L. fruits. Journal of Pest Science, 1-11. doi: 10.1007/s10340-013-0516-8

Ricco, R. A., Wagner, M. L., Portmann, E., Reides, C., Llesuy, S., Gurni, A. A., \& Carballo, M. A. (2010). Análisis de polifenoles, actividad antioxidante y genotoxicidad en especies argentinas de Lippia y Aloysia (Verbenaceae). Boletín Latinoamericano y del Caribe de Plantas Medicinales y Aromáticas, 9(5).

Rimm, E. B., Katan, M. B., Ascherio, A., Stampfer, M. J., \& Willett, W. C. (1996). Relation between intake of flavonoids and risk for coronary heart disease in male health professionals. Annals of internal medicine, 125(5), 384-389.
Sagredo, B., Lorenzen, J., Casper, H., \& Lafta, A. (2011). Linkage analysis of a rare alkaloid present in a tetraploid potato with Solanum chacoense background. Theoretical and Applied Genetics, 122(3), 471-478. doi: 10.1007/s00122010-1461-z

Saigne, C., Richard, T., Mérillon, J.-M., \& Monti, J.-P. (2006). 13C NMR analysis of polyphenol biosynthesis in grape cells: Impact of various inducing factors. Analytica Chimica Acta, 563(12), 137-144. doi: http://dx.doi.org/10.1016/j. aca.2005.09.073

Saleem, A., Husheem, M., Härkönen, P., \& Pihlaja, K. (2002). Inhibition of cancer cell growth by crude extract and the phenolics of Terminalia chebula retz. fruit. Journal of Ethnopharmacology, 81(3), 327-336.

Shahidi, F., \& Ambigaipalan, P. (2015). Phenolics and polyphenolics in foods, beverages and spices: Antioxidant activity and health effects-A review. Journal of Functional Foods, 18, 820-897.

Skrovankova, S., Sumczynski, D., Mlcek, J., Jurikova, T., \& Sochor, J. (2015). Bioactive compounds and antioxidant activity in different types of berries. International journal of molecular sciences, 16(10), 24673-24706.

Sumczynski, D., Kotásková, E., Družbíková, H., \& Mlček, J. (2016). Determination of contents and antioxidant activity of free and bound phenolics compounds and in vitro digestibility of commercial black and red rice (Oryza sativa L.) varieties. Food Chemistry, 211, 339-346.

Surco-Laos, F., Valle Campos, M., Loyola, E., Dueñas, M., \& Santos, C. (2016). Actividad antioxidante de metabolitos de flavonoides originados por la microflora del intestino humano. Revista de la Sociedad Química del Perú, 82(1), 29-37.

Taguri, T., Tanaka, T., \& Kouno, I. (2004). Antimicrobial activity of 10 different plant polyphenols against bacteria causing food-borne disease. Biological and Pharmaceutical Bulletin, 27(12), 1965-1969.

Tocci, N., Weil, T., Perenzoni, D., Narduzzi, L., Madriñán, S., Crockett, S., . . . Mattivi, F. (2018). Phenolic profile, chemical relationship and antifungal activity of Andean Hypericum species. Industrial Crops and Products, 112, 32-37.

Tomás-Barberán, F. (2003). Los polifenoles de los alimentos y la salud. Alimentación Nutrición y Salud, 10(2), 41-53. 
Torrenegra Alarcón, M. E., Villalobos Lagares, O. L., Castellar Abello, E. A., León Méndez, G., Granados Conde, C., Pajaro, N. P., . . . Soledad, I. (2016). Evaluación de la actividad antioxidante de las pulpas de Rubus glaucus B, Vaccinium floribundum K y Beta vulgaris L. Revista Cubana de Plantas Medicinales, 21(4), 1-8.

Tsao, R. (2010). Chemistry and biochemistry of dietary polyphenols. Nutrients, 2(12), 1231-1246.

Valencia-Ortiz, C. (1995). Fundamentos de fitoquímica.

Varga, E., Bardocz, A., Belak, A., Maraz, A., Boros, B., Felinger, A., . . . Horvath, G. (2015). Antimicrobial activity and chemical composition of thyme essential oils and the polyphenolic content of different thymus extracts. Thymus, 63, 3 .

Vega, A., De León, J. A., \& Reyes, S. M. (2017). Determinación del Contenido de Polifenoles Totales, Flavonoides y Actividad Antioxidante de 34 Cafés Comerciales de Panamá. Información tecnológica, 28(4), 29-38.
Wilkinson, J. A., Rossington, S. B., Ducki, S., Leonard, J., \& Hussain, N. (2006). Asymmetric alkylation of diarylmethane derivatives. Tetrahedron, 62(8), 1833-1844.

Yi, Z.-C., Liu, Y.-Z., Li, H.-X., Yin, Y., Zhuang, F.-Y., Fan, Y.-B., \& Wang, Z. (2006). Tellimagrandin I enhances gap junctional communication and attenuates the tumor phenotype of human cervical carcinoma HeLa cells in vitro. Cancer letters, 242(1), 77-87.

You, Y.-c., Yang, G., Wang, A.-I., \& Li, D.-p. (2005). Synthesis of intermediate for lamellarin $\mathrm{H}$. Current Applied Physics, 5(5), 535-537.

Zadra, M., Piana, M., Brum, T. F. d., Boligon, A. A., Freitas, R. B. d., Machado, M. M., . . A Athayde, M. L. (2012). Antioxidant Activity and Phytochemical Composition of the Leaves of Solanum guaraniticum A. St.-Hil. Molecules, 17(11), 1256012574. doi: $10.3390 /$ molecules 171112560

Ziegler, J., \& Facchini, P. J. (2008). Alkaloid biosynthesis: metabolism and trafficking. Annual Review of Plant Biology, 59, 735-769. 